Jurnal Tabarru' : Islamic Banking and Finance

Volume 4 Nomor 1, Mei 2021

p-ISSN 2621-6833

e-ISSN 2621-7465

\title{
INDEKS LITERASI WAKAF GENERASI MILENIAL
}

\author{
Astika Rahmah Ghanny ${ }^{1}$ \& Nur Fatwa ${ }^{2}$ \\ ${ }^{I}$ Mahasiswa Program Pascasarjana Kajian Timur Tengah, Universitas Indonesia \\ ${ }^{2}$ Dosen Program Pascasarjana Kajian Timur Tengah, Universitas Indonesia \\ Email : astikarg@gmail.com,nurfatwa@ui.ac.id
}

\begin{abstract}
ABSTRAK
Indeks literasi wakaf sebagai alat ukur yang digunakan untuk mengetahui pemahaman masyarakat tentang wakaf secara komprehensif dan akurat. Adanya gagasan indeks literasi wakaf memiliki peran penting bagi para peneliti untuk memiliki alat ukur dalam menilai tingkat pemahaman wakaf di masyarakat. Hasil pengukuran tingkat pemahaman generasi milenial wakaf yang diukur menggunakan alat ukur indeks literasi wakaf, ditemukan bahwa generasi milenial di Jakarta memiliki skor 36,71\% (kategori rendah) dari 100 responden survei di Provinsi DKI Jakarta.
\end{abstract}

\section{Kata kunci : Wakaf, Literasi, Milenial, Indeks.}

\begin{abstract}
The wakaf literacy index as a measuring tool used in order to identify the understanding of the people about wakaf comprehensively and accurately. The existence of the idea of the wakaf literacy index has important role for scholars to have a measuring tool in evaluating the level of understanding of wakaf in society The results of measuring the level of understanding of the millennial generation of wakaf which is measured using the wakaf literacy index measuring instrument, it was found that the millennial generation in Jakarta has a score of $36.71 \%$ (Low) from 100 respondent surveys in Jakarta Province.
\end{abstract}

Keywords : Awqaf, Literacy, Millenials, Index. 


\section{PENDAHULUAN}

Berdasarkan kamus besar bahasa Indonesia arti dari literasi yaitu kemampuan menulis dan membaca. Menurut UNESCO (2006), literasi ialah seperangkat keterampilan nyata, terutama keterampilan dalam membaca dan menulis yang terlepas dari konteks yang mana ketrampilan itu diperoleh serta siapa yang memperolehnya. Pendapat lain mengatakan bahwa pengertian literasi adalah suatu kemampuan individu dalam mengolah dan memahami informasi ketika melakukan kegiatan membaca dan menulis. Dengan kata lain, literasi ialah seperangkat keterampilan dan kemampuan seseorang dalam membaca, menulis, berhitung serta memecahkan masalah dalam kehidupannya sehari-hari. Kegiatan literasi memang merujuk pada kemampuan dasar seseorang dalam membaca dan menulis. Sehingga selama ini, strategi yang dilakukan untuk meningkatkan kemampuan tersebut adalah menumbuhkan minat membaca dan menulis. Saat ini, istilah literasi sudah mulai digunakan dalam arti yang lebih luas, seperti literasi informasi, literasi komputer, dan literasi sains yang kesemuanya itu merujuk pada kompetensi atau kemampuan yang lebih dari sekedar kemampuan membaca dan menulis. Hanya saja, memang pemahaman yang paling umum mengenai literasi yaitu kemampuan membaca dan menulis.

Apabila dikaitkan dengan generasi milenial, generasi ini merupakan generasi yang mempunyai perilaku yang berbeda dengan generasi sebelumnya. Milenial atau sering disebut generasi $\mathrm{Y}$ adalah sekelompok orang yang lahir pada kisaran tahun 1980 hingga 2000-an. Beberapa perilaku yang dilakukan milenial yang berbeda dengan generasi sebelumnya diantaranya : perilaku pertama, generasi milenial di Indonesia yaitu sangat kecanduan internet. Dalam sehari rata-rata generasi milenial bisa menggunakan internet dengan durasi lebih dari tujuh jam dengan rentang usia tertentu. Kedua, pengembangan diri atau self-improvement ini juga menjadi hal yang sangat menarik perhatian generasi $\mathrm{Y}$ ini yaitu keinginan untuk melaksanakan pengembangan diri agar dapat menjadi pribadi yang lebih baik daripada sebelumnya. Ketiga, generasi milenial bisa bekerja dengan lebih cepat dan cerdas lantaran didukung oleh keberadaan teknologi. Perkembangan teknologi juga mendorong milenial memiliki kemampuan multi-tasking. Perilaku ini membuat milenial terbiasa melakukan dua hingga tiga pekerjaan sekaligus. Lalu bagaimana tingkat literasi generasi $\mathrm{Y}$ ini jika dilihat dari perilaku yang dilakukan oleh milenial ini apakah memiliki tingkat literasi yang tinggi?, lebih khusus tingkat literasi wakaf.

Pusat Kajian Strategis Badan Amil Wakaf Nasional bekerja sama dengan Direktorat Pemberdayaan Wakaf dan Wakaf Kementerian Agama Republik Indonesia pada tahun 2019 menerbitkan konsep indeks literasi wakaf (ILW). ILW merupakan alat ukur yang digunakan dalam rangka mengidentifikasi pemahaman masyarakat Indonesia mengenai wakaf secara komprehensif dan akurat. Pengukuran ini dilakukan di 32 provinsi menggunakan pendekatan metode ILW. Dengan melibatkan 3200 responden di 32 Provinsi di Indonesia, hasil survey menemukan bahwa secara nasional nilai tingkat literasi wakaf mendapatkan skor 66.78 yang masuk dalam kategori tingkat literasi wakaf menengah atau moderat. Dalam aspek perilaku wakif dalam menunaikan wakaf, Bulan Ramadhan menjadi waktu yang paling banyak dipilih oleh masyarakat dalam menunaikan wakaf yaitu sebesar 55\%. Kemudian, tempat pembayaran wakaf yang paling banyak dipilih oleh masyarakat adalah Masjid atau Musholla yaitu sebesar 37\%. Lebih lanjut, faktor 
aksesabilitas atau jangkauan tempat menunaikan wakaf menjadi faktor paling dominan yang dipilih oleh masyarakat dalam menunaikan wakaf yaitu sebesar $50 \%$. Selanjutnya, hasil survey juga menemukan bahwa sumber informasi wakaf yang paling dominan adalah berasal dari ceramah agama yakni sebesar $46 \%$ (Puskas BAZNAS, 2019).

Keberadaan konsep ILW menjadi sangat penting bagi para pemangku kepentingan agar memiliki alat ukur dalam mengevaluasi tingkat pemahaman wakaf di masyarakat. Dari nilai implementasi ILW yang telah dilakukan dapat dapat membantu stakeholder yang berkepentingan dalam mengidentifikasi nilai literasi berbasis wilayah. Selain itu, hasil kajian ini juga dapat dijadikan sebagai feedback bagi otoritas wakaf untuk mengidentifikasi dan mengevaluasi efektifitas program edukasi dan sosialisasi wakaf, sehingga otoritas wakaf dapat mengeluarkan regulatory instrument yang tepat.

\section{TINJAUAN PUSTAKA}

Indonesia segera akan memasuki fenomena bonus demografi beberapa tahun ke depan. Fenomena ini ditandai dengan meningkatnya jumlah penduduk produktif secara signifikan. Meningkatnya jumlah penduduk produktif tentunya menjadi peluang emas untuk menggerakkan roda perekonomian. Penduduk produktif pada era ini didominasi oleh generasi $\mathrm{Y}$ atau generasi milenial. Bonus demografi pada dasarnya tidak terlepas dari generasi milenial. Berdasarkan penjelasan sebelumnya, rasio ketergantungan Indonesia tahun 2015 sebesar 49,20 secara tidak langsung memiliki makna bahwa persentase jumlah penduduk usia produktif mencapai sekitar 67,02 persen dari jumlah penduduk keseluruhan. Selanjutnya, jika persentase jumlah penduduk usia produktif ini dikaitkan dengan persentase generasi milenial tahun 2017 yang sebesar 33,75 persen dari jumlah penduduk keseluruhan. Ini berarti sumbangan generasi milenial dalam membentuk struktur jumlah penduduk usia produktif tergolong cukup tinggi, karena sekitar 50,36 persen dari jumlah penduduk usia produktif pada dasarnya merupakan generasi milenial (asumsi : rasio ketergantungan 2015 dan 2017 sama besar). Sebagai penduduk terbesar, tentunya generasi milenial akan berperan besar pada era bonus demografi. Generasi ini yang akan memegang kendali atas roda pembangunan khususnya di bidang perekonomian yang diharapkan akan mampu membawa bangsa Indonesia menuju ke arah pembangunan yang lebih maju dan dinamis.

\section{Generasi Milenial}

Dalam artikel Milennial Trends, Generasi milenial (Millennial Generation) adalah generasi yang lahir dalam rentang waktu awal tahun 1980 hingga tahun 2000. Generasi ini sering disebut juga sebagai Gen-Y, Net Generation, Generation WE, Boomerang Generation, Peter Pan Generation, dan lain-lain. Mereka disebut generasi milenial karena merekalah generasi yang hidup di pergantian milenium. Secara bersamaan di era ini teknologi digital mulai merasuk ke segala sendi kehidupan. Berdasarkan hasil penelitian dari Lancaster \& Stillman (2002) Generasi Y dikenal dengan sebutan generasi millenial atau milenium. Ungkapan generasi Y mulai dipakai pada editorial koran besar Amerika Serikat pada Agustus 1993. Generasi ini banyak menggunakan teknologi komunikasi instan seperti email, SMS, instant messaging dan media sosial seperti facebook dan twitter, IG dan lain-lain, sehingga dengan kata lain generasi $Y$ adalah generasi yang tumbuh pada era internet booming. Berdasarkan definisi tersebut dapat ditarik kesimpulan bahwa generasi milenial adalah generasi yang lahir diantara tahun 1980-2000 saat terjadi 
kemajuan teknologi yang pesat. Jika dilihat dari kelompok umur, generasi milenial merupakan generasi yang saat ini berusia dikisaran 15-35 tahun.

\section{Karakteristik Generasi Milenial}

Berdasarkan literatur dari artikel Hitss.com, diketahui ada beberapa macam karakteristik dari generasi milenial yaitu: 1) Milenial lebih percaya user generated content (UGC) daripada informasi searah, 2) Milenial lebih memilih ponsel dibanding TV, 3) Milenial wajib punya media sosial, 4) Milenial kurang suka membaca secara konvensional, 5) Milenial cenderung tidak loyal namun bekerja efektif, 6) Milenial cenderung melakukan transaksi secara cashless, 7) Milenial lebih tahu teknologi dibanding orang tua mereka, 8) Milenial memanfaatkan teknologi dan informasi, 9) Milenial cenderung lebih malas dan konsumtif, dan lain-lain.

\section{Pengertian Wakaf}

Wakaf menurut bahasa Arab berarti "al-habsu", yang berasal dari kata kerja habasa-yahbisu-habsan, menjauhkan orang dari sesuatu atau memenjarakan. Kemudian kata itu berkembang menjadi "habbasa" dan berarti mewakafkan harta karena Allah SWT. Kata wakaf sendiri berasal dari kata kerja waqafa (fi'il madhi)-yaqifu (fi'il mudhari')-waqfan (isim masdar) yang berarti berhenti atau berdiri. Sedangkan wakaf menurut istilah syara' adalah "menahan harta yang mungkin diambil manfaatnya tanpa menghabiskan atau merusakkan bendanya (ainnya) dan digunakan untuk kebaikan". (Adijani AlAlabij, 1997)

Menurut Fathurrohman (2013) mendifinisikan wakaf adalah perbuatan hukum wakif untuk menahan harta benda miliknya, baik sementara waktu maupun untuk selamanya, dimanfaatkan secara berulang untuk kepentingan umum maupun untuk kepentingan khusus yang sesuai dengna prinsip syari'at Islam.

Dalam peraturan pemerintah Republik Indonesia nomor 42 Tahun 2006 menyebutkan bahwa Wakaf adalah perbuatan hukum wakif untuk memisahkan dan/atau menyerahkan sebagian harta benda miliknya untuk dimanfaatkan selama-lamanya atau untuk jangka waktu tertentu sesuai dengan kepentinganya guna keperluan ibadah dan/atau kesejahteraan umum menurut syariah. Menurut istilah wakaf berarti berhenti atau menahan harta yang dapat diambil manfaatnya tampa musnah seketika dan untuk pengunaan yang mubah, serta dimaksudkan untuk mendapatkan keridhoan Allah SWT.

Syafi'i dan Hambal berpendapat bahwa wakaf adalah melepaskan harta yang diwakafkan dari kepemilikan wakif, setelah sempurna prosedur perwakafan. Wakif tidak boleh melaukan apa saja terhadap harta yang diwakafkan, seperti: perlakuan pemilik dengan cara pemilikannya kepada yang lain, baik dengan tukaran atau tidak. Jika wakif wakat, harta-harta yang diwakafkan tersebut tidak diwarisi oleh ahli warisnya. Wakif menyalurkan manfaat harta yang diwakafkannya tersebut. Apabila wakif melarang, maka hakim berhak memaksanya agar memberikannya kepada kedua belah pihak (mauquf 'alaih).

Menurut Qahaf (2006) juga membagi wakaf menjadi tiga kategori :

a. Wakaf sosial (khairi)

b. Wakaq untuk keluarga (ahli) dan,

c. Wakaf gabungan (musytaraka).

Sedangkan menurut Hamzah (2016) Wakaf merupakan salah satu instrumen keuangan Islam yang mempunyai fungsi cukup penting dalam perkembangan perekonomian Islam terutama bagi perekonomian negaranegara Muslim termasuk Indonesia. Oleh 
karenanya wakaf dapat dijadikan sebagai salah satu sumber keuangan bagi pembangunan negara-negara Muslim yang harus dikelola secara professional untuk kemaslahatan masyarakat pada umumnya.

\section{Penelitian Terdahulu}

Penelitian yang dilakukan oleh Machmud dan Suryaningsih (2020) yang berjudul Analisis Tingkat Literasi Wakaf Uang Mahasiswa Fakultas Ekonomi Universitas Negeri Surabaya. Hasil dari penelitian tersebut dapat memberikan gambaran bagi stakeholder bagaimana kondisi yang ada di lingkungan Fakultas Ekonomi. Terbukti dengan hasil penelitian, hanya siswa Program Studi Ekonomi Islam yang memiliki pengetahuan di atas rata-rata siswa jurusan lainnya tetapi masih diklasifikasikan ke dalam level rendah karena pengetahuan mahasiswa Program Studi Ekonomi Islam hanya sebatas pengetahuan dasar.

Penelitian yang dilakukan oleh Muhammad (2020) yang berjudul Analisa Program Kelas Literasi Zakat dan Wakaf di Masa Covid 19. Hasil penelitian menunjukkan bahwa program kelas literasi zakat wakaf menunjukkan adanya peningkatan pemahaman megenai zakat dan wakaf serta motivasi terbesar untuk menambah pengetahuan, mendapatkan sertifikat dan mendapatkan relasi jaringan. Adapun untuk saran kelas lanjutan literasi zakat dan wakaf, mayoritas responden menyatakan bahwa diperlukannya diadakan secara rutin setiap bulan.

Penelitian yang dilakukan oleh Zulkifli dan Ali (2019) yang berjudul Persepsi Nazhir di Kecamatan Sukajadi Kota Pekanbaru terhadap Wakaf Produktif. Dari 45 responden yang diteliti $14 \%$ menyatakan sangat setuju, $76 \%$ menyatakan setuju, $8 \%$ menyatakan netral, $2 \%$ menyatakan tidak setuju, dan $0 \%$ menyatakan sangat tidak setuju. Berada pada rata-rata skor sebesar 177 terletak pada daerah setuju digaris kontinum. Hasil penelitian menunjukkan bahwa nazhir "setuju" dengan wakaf produktif.

\section{METODE PENELITIAN}

Populasi penelitian yang digunakan dalam objek penelitian ini adalah generasi milenial yang berada di wilayah survei. Tujuan pemilihan objek penelitian ini adalah mengukur tingkat literasi wakaf generasi milenial. Pemilihan sampel responden yang diterapkan dalam penelitian ini dengan metode non probability sampling dengan menggunakan teknik purposive sampling dimana pengambilan sampel responden didasarkan pada kriteria-kriteria yang telah ditetapkan (Juanda, 2009). Adapun wilayah yang menjadi target dalam penelitian ini ada di Provinsi DKI Jakarta. Jenis data yang digunakan dalam pengukuran ILW adalah data primer dengan metode wawancara. Pemilihan responden untuk generasi milenial ini yaitu ada pada rentang usia produktif yang dimulai dari usia 17-45 tahun. Adapun sumber data yang didapatkan berasal dari 100 responden yang tersebar di provinsi DKI Jakarta dengan pengambilan data dimulai dari Bulan Maret-Mei 2020.

Penelitian ini, dalam hal mengukur literasi wakaf generasi milenial, menggunakan metode perhitungan ILW yang telah dikonstruksi oleh Puskas BAZNAS. Penghitungan ILW menggunakan pendekatan Simple Weighted Index atau setiap indikator akan diberikan bobot yang sama. Secara matematis, penghitungan Simple Weighted Index dapat dilihat sebagai berikut :

$$
\begin{aligned}
I L Z= & \left(\bar{X} \sum_{i=1}^{N}\left(\text { Score }_{i b s c} \times \operatorname{Smp} b s c W_{i} \times 100\right)\right) \times W_{v i} b s c \\
& +\left(\bar{X} \sum_{i=1}^{N}\left(\text { Score }_{i a d v} \times \operatorname{Smp} A d v W_{i} \times 100\right)\right) \times W_{v i} A d v
\end{aligned}
$$


Keterangan :

$\begin{array}{lll}\text { ILW } & \text { Total Indeks Literasi } \\ & \text { Wakaf } \\ \text { Score }_{\text {ibsc }} & : \begin{array}{l}\text { Skor yang didapat pada } \\ \text { indikator i di dimensi } \\ \text { dasar }\end{array}\end{array}$

Smp bcs $W_{i} \quad$ : Nilai Pembobotan pada indikator $i$ pada dimensi pengetahuan dasar Indeks Literasi Wakaf

Score iadv : Skor yang didapat pada indikator $i$ di dimensi lanjutan

$\operatorname{Smp} A d v W_{i} \quad$ : Nilai Pembobotan pada indikator $i$ pada dimensi pengetahuan lanjutan Indeks Literasi Wakaf

$W_{v i} b s c \quad:$ Nilai pembobotan pada variabel $i$ di dimensi pengetahuan dasar

$W_{v i} A d v \quad:$ Nilai pembobotan pada variabel $i$ di dimensi pengetahuan lanjutan

Tahapan penghitungan nilai ILW untuk milenial terdiri dari tiga tahap. Tahap pertama, pembobotan nilai setiap indikator-indikator pada variabel ILW akan dihitung. Pada pada tahap kedua, akan dihitung nilai ILW pada masingmasing variabel untuk mendapatkan nilai ILW pada tataran dimensi. Kemudian pada tahap terakhir, nilai ILW pada masing-masing dimensi akan ditambahkan untuk mendapatkan nilai keseluruhan ILW.

Pada tahap awal SWI dilakukan pembobotan pada masing masing indikator baik itu pada dimensi dasar dan dimensi lanjutan sebagaimana berikut:

Smp bsc ILW $W_{i} \quad=$ $\frac{1}{N}$

Keterangan :

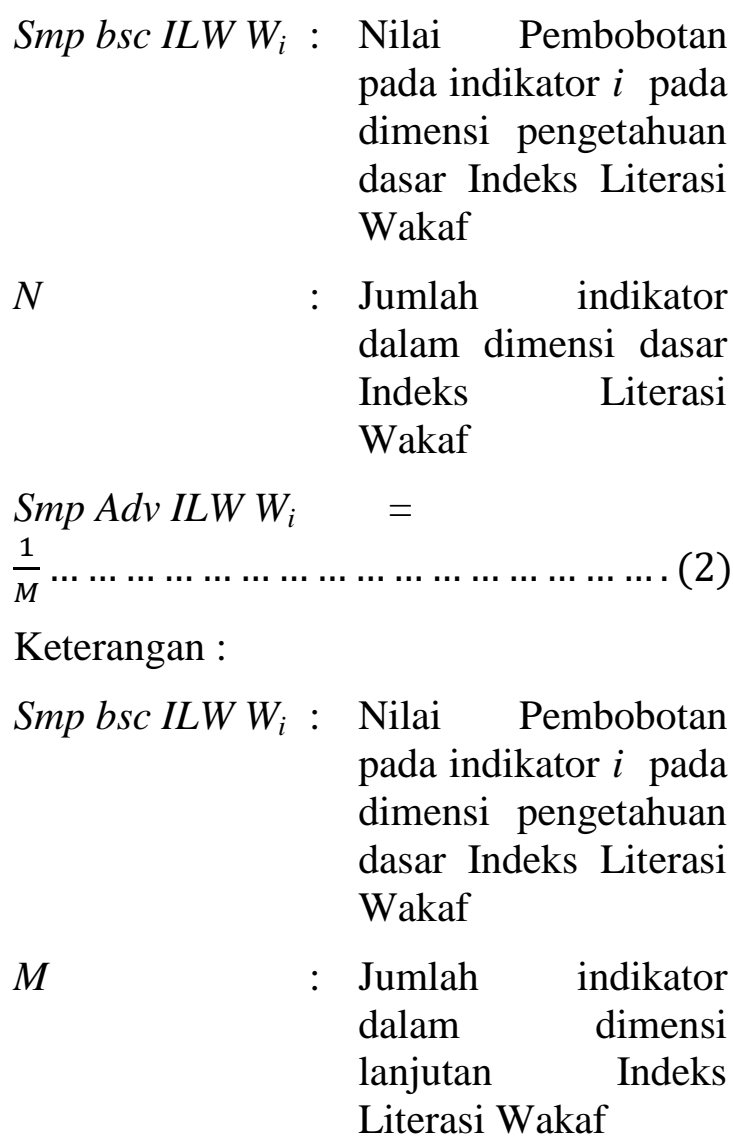

Tahap selanjutnya, penghitungan ILW akan dilakukan pada tataran dimensi baik pada dimensi pengetahuan dasar dan juga dimensi pengetahuan lanjutan tentang wakaf. Keseluruhan konsep penghitungan pada masing-masing dimensi dapat dilihat sebagaimana berikut:

Basic ILW=

$$
\begin{aligned}
& \left(\bar{X} \sum_{i=1}^{N}\left(\text { Score }_{i} \times \operatorname{Smp} b s c W_{i} \times 100\right)\right) \\
& x W_{v i} b s c \ldots \ldots(3)
\end{aligned}
$$

Keterangan :

Basic ILW : Total nilai pembobotan Indeks Literasi Wakaf pada dimensi dasar

Score $_{i} \quad$ : Skor yang didapat pada indikator i di dimensi pengetahuan dasar

Smp bsc $W_{i}$ : Nilai pembobotan pada indikator i pada dimensi 
pengetahuan dasar Indeks Literasi Wakaf

$\mathrm{W}_{\mathrm{vi}}$ bsc : Nilai pembobotan pada variabel i di dimensi dasar

Advance $I L W=$

$\left(\bar{X} \sum_{i=1}^{N}\left(\operatorname{Score}_{i} \times \operatorname{Smp} A d v W_{i} \times 100\right)\right)$

$x W_{v i} b s c$

Keterangan :

Advance ILW : Total nilai pembobotan Indeks Literasi Wakaf pada dimensi pengetahuan lanjutan

Score $_{i} \quad:$ Skor yang didapat pada indikator $\mathrm{i}$ di dimensi pengetahuan lanjutan

$\operatorname{Smp} A d v W_{i} \quad$ : Nilai pembobotan pada indikator i pada dimensi pengetahuan lanjutan Indeks Literasi Wakaf

$W_{v i} A d v \quad$ : Nilai pembobotan pada variabel i di dimensi pengetahuan lanjutan

Pada tahap terakhir penghitungan total ILW dilakukan dengan menjumlahkan ILW pada dimensi pengetahuan dasar dan nilai ILW pada pengetahuan lanjutan sebagaimana berikut:

Total ILW $=\left(\right.$ Basic ILWx $\left.W_{b}\right)+$ (Advance ILWX $\left.W_{a}\right)$
Keterangan :

Total ILW : Total skor Indeks Literasi Wakaf

Basic ILW : Total nilai Indeks Literasi Wakaf pada dimensi pengetahuan dasar tentang wakaf

Basic ILW : Total nilai Indeks Literasi Wakaf pada dimensi pengetahuan dasar tentang wakaf

Advance ILW : Total nilai Indeks Literasi Wakaf pada dimensi pengetahuan lanjutan tentang wakaf

$W_{b} \quad$ : Nilai pembobotan pada dimensi pengetahuan dasar tentang wakaf

$W_{a} \quad:$ Nilai pembobotan pada dimensi pengetahuan lanjutan tentang wakaf

Penentuan kriteria penilaian ILW terdiri dari tiga kategori dengan rentang nilai. Hasil pengukuran dengan rentang nilai 0.00-60.00 masuk dalam kategori tingkat literasi yang rendah. Kategori tingkat literasi menengah atau moderat apabila hasil pengukuran masuk dalam rentang nilai >60.00-80.00. Hasil pengukuran tingkat literasi tinggi apabila mendapat rentang nilai $>80.00-00$.

Tabel 1. Rentang Nilai Indeks Literasi Wakaf

\begin{tabular}{lll}
\hline No. & \multicolumn{1}{c}{ Rentang Nilai } & \multicolumn{1}{c}{ Kategori } \\
\hline 1 & $0.00-60.00$ & Tingkat Literasi Rendah \\
\hline 2 & $>60.00-80.00$ & Tingkat Literasi Menengah atau Moderat \\
\hline 3 & $>80.00-100$ & Tingkat Literasi Tinggi
\end{tabular}




\section{HASIL DAN PEMBAHASAN}

Pengukuran indeks literasi wakaf pada kaum milenial melibatkan 100 responden yang tersebar di Provinsi DKI Jakarta. pemilihan responden dengan metode Non Probability Sampling dengan menggunakan teknik purposive sampling dimana pengambilan sampel responden didasarkan pada kriteria-kriteria yang telah ditetapkan (Juanda, 2009).

Tabel 2. Jenis Responden Menurut Jenis Kelamin

\begin{tabular}{ccc}
\hline No. & \multicolumn{1}{c}{ Jenis } & Jumlah \\
\hline 1. & Responden Laki-Laki & $30 \%$ \\
\hline 2. & Responden Wanita & $70 \%$ \\
\hline \multicolumn{3}{c}{ Sumber $\cdot$ Data Olahan (2021) }
\end{tabular}

Penelitian ini khusus membahas tingkat literasi wakaf kepada generasi milenial, sehingga mereka yang berusia 17-45 tahun dipilih menjadi responden dalam penelitian ini. Tabel 2 mempresentasikan responden berdasarkan gender dengan keterlibatan laki-laki 30\% lebih sedikit ketimbang perempuan $70 \%$.

Tabel 3. Responden Berdasarkan Jenis Pekerjaan

\begin{tabular}{llr}
\hline No. & \multicolumn{1}{c}{ Jenis Pekerjaan } & Jumlah Pekerjaan \\
\hline 1. & Wirausaha & $21 \%$ \\
\hline 2. & Pegawai Swasta & $52 \%$ \\
\hline 3. & Pendidik/ulama & $15 \%$ \\
\hline 4. & OB & $1 \%$ \\
\hline 5. & Mahasiswa/Pelajar & $8 \%$ \\
\hline 6. & ASN & $2 \%$ \\
\hline 7. & Pegawai BUMN & $1 \%$ \\
\hline & Sumber : Data Olahan (2021)
\end{tabular}

Selanjutnya, pekerjaan responden milenial dari jumlah sampel yang telah diteliti dijelaskan pada Tabel 3. Milenial yang terlibat dalam penelitian ini didominasi oleh mereka yang bekerja sebagai pegawai swasta yaitu sebanyak $52 \%$, sedangkan paling sedikit sebanyak $1 \%$ responden yang bekerja sebagai Pegawai BUMN dan OB. Selain itu responden yang bekerja sebagai pelajar dan mahasiswa sebesar $8 \%$ dan mereka yang sebagai wirausaha sebanyak $21 \%$ serta $15 \%$ responden yang menjawab dengan kategori pekerjaan Pendidik/ulama. Pendapatan responden pada penelitian ini akan dibagi menjadi tiga rentang yaitu mereka yang berpendapatan di bawah < Rp. 7.500.000, diantara Rp. 7.500.000 - Rp. 17.500.000, dan diatas Rp. 17.500.000. Berdasarkan tingkat pendapatan yang dijelaskan pada Tabel 4 diketahui bahwa sebagian besar responden memiliki pendapatan < Rp. 7.500.000 yaitu sebanyak 82 responden dan hanya 16 responden yang memiliki pendapatan Rp. $7.500 .000-$ Rp. 17.500.000, sedangkan sisanya memiliki pendapatan di bawah >Rp 17.500.000 sebanyak 2 responden. 
Tabel 4. Responden Berdasarkan Jenis Upah

\begin{tabular}{clc}
\hline No. & \multicolumn{1}{c}{ Upah } & Jumlah \\
\hline 1. & $<\operatorname{Rp~7.500.000}$ & 82 \\
\hline 2. & Rp 7.500.000 - Rp 17.500.000 & 16 \\
\hline 3. & $>\operatorname{Rp~17.500.000}$ & 2 \\
\hline
\end{tabular}

Sumber : Data Olahan (2021)

Menurut hasil penelitian dari Kementerian Agama Republik Indonesia yang telah mensurvei secara nasional di 32 provinsi di Indonesia, didapatkan bahwa masyarakat Indonesia memiliki tingkat literasi wakaf yang rendah moderat dengan perolehan nilai Indeks Literasi Wakaf (ILW) secara Nasional secara keseluruhan mendapatkan skor 50,48 masuk dalam kategori rendah Terdiri dari Nilai Literasi Pemahaman Wakaf Dasar sebesar 57,67 dan Nilai Literasi Pemahaman Wakaf Lanjutan sebesar 37,97.

Seperti yang telah dijelaskan sebelumnya, penelitian ini hanya fokus pada kaum milenial dengan kategori usia 17-45 tahun. Hal ini didasarkan pada usia dalam rentang tersebut merupakan usia produktif dan memiliki tingkat kegairahan terhadap sesuatu yang cukup tinggi dan menyukai tantangan. Kenyataan ini pun menarik untuk dikaji bagaimana tingkat literasi kaum milenial terhadap pengetahuan tentang wakaf.

Indeks literasi wakaf sebagai alat ukur dibangun oleh dua indikator yaitu indikator pemahaman dasar tentang wakaf dan pemahaman lanjutan tentang wakaf. Adapun masing-masing indikator dijelaskan dengan variabel pemahaman wakaf secara umum, kewajiban membayar wakaf, wakif, penghitungan wakaf, objek wakaf, institusi wakaf, regulasi wakaf, dampak wakaf, program wakaf hingga ke pemahaman terkait wakaf digital. Hasil dari pengukuran tingkat pemahaman generasi milenial terhadap wakaf yang diukur menggunakan alat ukur ILW yang dikembangkan oleh Puskas BAZNAS didapatkan bahwa generasi milenial memiliki skor ILW sebesar 36.71 (rendah). hal ini menggambarkan bahwa generasi milenial di Provinsi DKI Jakarta memiliki pemahaman terkait wakaf yang rendah.

\section{KESIMPULAN}

Secara keseluruhan, hasil dari penelitian ini menggambarkan tingkat pemahaman literasi wakaf kaum milenial baik terkait pemahaman dasar maupun pemahaman lanjutan. Sama seperti kriteria nilai ILW Provinsi DKI Jakarta, kaum milenial memiliki tingkat pemahaman terhadap wakaf sebesar 36.71 (rendah) atau masuk dalam kategori rendah. Bonus demografi yang dimiliki Indonesia terhadap kaum milenial merupakan suatu keuntungan bagi negara namun dilain sisi belum sebanding dengan tingkat pemahaman anak muda terkait pentingnya wakaf. Berdasarkan hasil penelitian di atas, peneliti juga merekomendasikan bagi lembaga wakaf menjadikan kaum milenial sebagai sasaran sebagai wakif baru jika belum berwakaf dan atau mempertahankan mereka sebagai calon wakif bila mereka belum menunaikan kewajiban wakaf. Oleh karena itu, lembaga wakaf dan tokoh masyarakat bersama negara berkewajiban untuk memiliki strategi bagaimana menyadarkan kaum milenial terhadap wakaf khusus bagi yang memiliki pemahaman yang rendah serta memanfaatkan kaum milenial yang memiliki tingkat pemahaman yang tinggi. Penting bagi lembaga wakaf untuk mensosialisasikan pengetahuan dasar terkait wakaf dan juga memiliki strategi khusus untuk memiliki cara bagaimana 
menginformasikan terkait pengetahuan wakaf lanjutan kepada kaum milenial dengan cara yang unik dan elegan sesuai dengan karakteristiknya. Selain itu, menarik untuk lembaga wakaf membuat pemetaan potensi wakif milenial dari penilaian ILW agar pesan dari wakaf dapat tersampaikan kepada kaum milenial.

\section{DAFTAR PUSTAKA}

Adijani, Al-Alabij. 1997. Perwakafan Tanah di Indonesia dalam Teori dan Praktek. PT. Raja Grafindo Persada. Jakarta.

Faturrahman, Tata. 2013. Peluang Wakaf Produktif untuk pembiayaan Pendidikan Islam. Jurnal Wakaf dan Ekonomi Islam (Al Awqaf), 6(1).

Hamzah, Zulfadli. 2016. Peran Nazir dalam Mengembangkan Wakaf Produktif. Jurnal Ekonomi KIAT, 26(1), p. 76-89.

Juanda, B. 2009. Metode Penelitian Ekonomi dan Bisnis. IPB Press. Bogor.

Lancaster, L. C., \& Stillman, D. 2002. When Generations Collide: Who They Are. Why They Clash. How to Solve the Generational Puzzle at Work. Harper Collins. New York.

Machmud, Aqidatul Izzah., \& Suryaningsih, Sri Abidah. 2020. Analisis Tingkat Literasi Wakaf Uang Mahasiswa Fakultas Ekonomi Universitas Negeri Surabaya. Jurnal Ekonomika dan Bisnis Islam, 3(3), p. 165-179.

Muhammad, Iqbal Fadli. 2020. Analisa Program Kelas Literasi Zakat dan Wakaf di Masa Covid 19, Jurnal Bimas Islam, 13(2), p. 259-288.
Puskas BAZNAS. 2019. Indeks Literasi Wakaf : Teori dan Konsep. Pusat Kajian Strategis Badan Amil Wakaf Nasional Republik Indonesia. Jakarta.

Qahaf, Mundzir. 2006. Al Waqfu Al Islami-Tathawwuruhu, Iradatuhu, Tanmiyatuhu. Daar al Fikr al Mua'shir. Beirut.

UNESCO. 2006. Literacy. Dikutip pada tanggal 9 Mei 2021 dari http://www.unesco.org/new/en/edu cation/themes/education-buildingblocks/literacy/.

Zulkifli., \& Ali, Rahma Febriani. 2019. Persepsi Nazhir di Kecamatan Sukajadi Kota Pekanbaru terhadap Wakaf Produktif. Jurnal Tabarru' : Islamic Banking and Finance, 2(2), p. 16-27. 